\title{
Communication Technology Preferences of Hospitalized and Institutionalized Frail Older Adults During COVID-19 Confinement: Cross-Sectional Survey Study
}

Guillaume Sacco ${ }^{1,2,3}$, MD, PhD; Sébastien Lléonart ${ }^{4}, \mathrm{MD}$; Romain Simon ${ }^{1,3}, \mathrm{MS} ;$ Frédéric Noublanche $^{1,2,3}$, MS; Cédric Annweiler ${ }^{1,2,3,5}, \mathrm{MD}, \mathrm{PhD}$; TOVID Study Group ${ }^{1,4,6}$

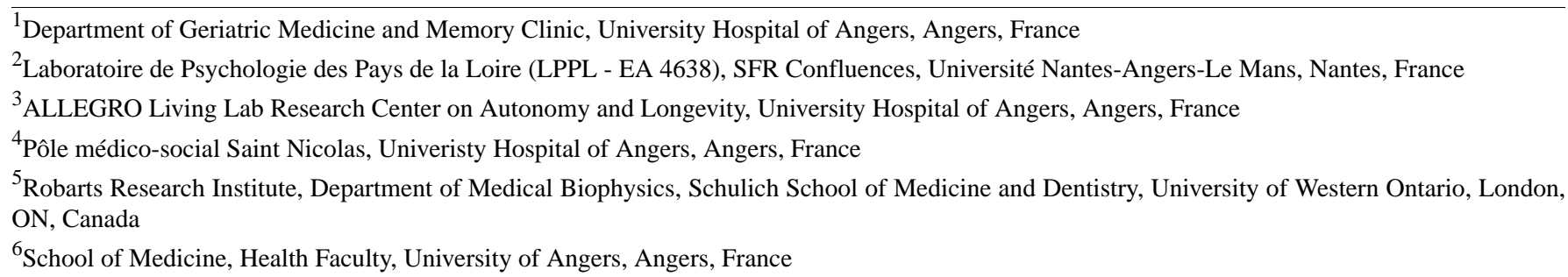

\section{Corresponding Author:}

Guillaume Sacco, MD, PhD

Department of Geriatric Medicine and Memory Clinic

University Hospital of Angers

4 Rue Larey

Angers

France

Phone: 33609733254

Email: yogisacco@gmail.com

\section{Abstract}

Background: Technological communication methods such as telephone calls and video calls can help prevent social isolation and loneliness in frail older adults during confinement.

Objective: Our objectives were to determine which virtual communication method (ie, telephone call or video call) was preferred by confined older hospital patients and nursing home residents and the variables influencing this preference.

Methods: The TOVID (Telephony Or Videophony for Isolated elDerly) study was a cross-sectional study that was designed to examine the preference between telephone calls and video calls among frail older adults who were either hospitalized in a geriatric acute care unit or institutionalized in a long-term care and nursing home during the COVID-19 confinement period.

Results: A total of 132 older people were surveyed between March 25 and May 11, 2020 (mean age 88.2 years, SD 6.2); 79 $(59.8 \%)$ were women. Patients hospitalized in the geriatric acute care unit were more able to establish communication independently than residents institutionalized in the long-term care and nursing home $(P=.03)$ and were more satisfied with their communication experiences $(P=.02)$. Overall, older people tended to favor telephone calls $(73 / 132,55.3 \%)$ over video calls $(59 / 132,44.7 \%)$; however, their satisfaction degree was similar regardless of the chosen method $(P=.1)$, with no effect of age $(P=.97)$ or gender $(P=.2)$. In the geriatric acute care unit, the satisfaction degrees were similar for telephone calls $(40 / 41,98 \%)$ and video calls $(33 / 38,87 \%)$ in older patients $(P=.10)$. Conversely, in the long-term care and nursing home, residents were more satisfied with the use of video calls to communicate with their relatives $(14 / 15,93 \%)$ versus the use of telephone calls $(6 / 12,50 \% ; P=.02)$.

Conclusions: Older people confined to health care settings were able to complete telephone calls more independently than video calls, and they tended to use telephone calls more often than video calls. The satisfaction degrees were similar with both modalities and even greater with video calls among long-term care and nursing home residents when they were given assistance to establish communication.

Trial Registration: ClinicalTrials.gov NCT04333849: https://www.clinicaltrials.gov/ct2/show/NCT04333849.

(JMIR Mhealth Uhealth 2020;8(9):e21845) doi: $\underline{10.2196 / 21845}$ 


\section{KEYWORDS}

video communication; telephone; older adults; nursing home; hospital; confinement; elderly; COVID-19; communication; technology; social isolation; loneliness

\section{Introduction}

All serious epidemics, such as the COVID-19 pandemic, prompt social organizations to deeply rethink the services they offer, especially toward frail older adults. For instance, the visitation restrictions in geriatric care units and nursing homes, although essential to the control of the pandemic, have also become a major source of social isolation and loneliness for vulnerable populations [1-3]. The only remaining social link for patients and residents in these facilities during confinement has been virtual communication using a range of communication devices, notably telephone calls and video calls.

The use of video calls is currently increasing because of the innovative nature of video, which allows people to speak to and hear others, view their expressions, and establish richer relationships than may be possible with a simple telephone call [4]. The research question in this paper is whether video calling meets the real demands and expectations of older adults or whether they prefer more traditional communication methods, such as the telephone, to contact their relatives. Moreover, evidence from previous literature about the efficacy of electronic interventions to avoid social isolation among older adults is weak and inconsistent [5-7].

Like many other practitioners, from the start of the COVID-19 public health crisis and the first visit restrictions for hospitalized and institutionalized patients, we proposed to organize daily communications between the patients and their relatives to avoid excessive isolation [8,9]. Both telephone calls and video calls were offered to the patients. The main objective of this study was to determine which virtual communication mode was preferred by older patients confined in hospital or institutionalized in a nursing home. Our secondary aims were to identify the proportions of older patients and residents who could independently communicate with virtual support; to measure and compare the degrees of satisfaction following telephone calls and video calls; and to analyze the effects of age and context (hospitalization versus nursing home) on the communication mode choice of older adults.

\section{Methods}

\section{Design and Settings}

The cross-sectional TOVID (Telephony Or Videophony for Isolated elDerly) study was conducted in the geriatric acute care unit and in the long-term care unit and nursing home of the University Hospital of Angers, France, between March 25 and May 11, 2020, during the national confinement period in France. No outside visits to these hospital units were authorized during this period. The study was conducted in accordance with the ethical standards set forth in the Helsinki Declaration (1983) and was approved by the local ethics committee (number 2020/29). The study protocol was declared to the National Commission for Information Technology and Civil Liberties
(CNIL) under the number ar20-0030v0 (ClinicalTrials.gov identifier: NCT04333849).

\section{Participants}

All older adults consecutively hospitalized in the geriatric acute care unit and in the long-term care and nursing home were considered for inclusion in the study. Patients who refused to participate or who were unable to communicate with their relatives for medical reasons were not included in the study.

\section{Data Collection}

Health professionals accustomed to using communication devices visited all eligible patients at least once per day to offer to help them organize their communications with their relatives. All patients who expressed interest were offered either a telephone call or a video call, and they were clearly informed that they could receive assistance to establish communication if necessary. All cognitively intact patients who objected to any help were considered to be independently capable of establishing communication (ie, declarative measure). The details of the communication (application and equipment, schedule, and duration) were discussed with the relatives prior to the communication to ensure that the call proceeded smoothly and easily.

Data regarding the participants' age, gender, hospital unit (ie, geriatric acute care unit or long-term care and nursing home), independent ability to establish communication, preferred virtual communication mode, and degree of satisfaction toward the mode of communication were collected. The preferred virtual communication mode was identified using a standardized question with three options (nothing, telephone call, or video call). The satisfaction degree toward virtual communication was assessed after the communication using a 6-point Likert scale (with $1=$ not satisfied at all to $6=$ totally satisfied), and the proportion of people satisfied with the communication (defined as a score $\geq 5 / 6$ ) was analyzed.

\section{Number of Participants}

Because the main objective of the study was descriptive, it was not necessary to calculate the number of subjects. However, to match a normal distribution of the data and to use parametric statistical tests, at least 30 participants were required in each group (ie, $n=30$ in the telephone call group and $n=30$ in the video call group).

\section{Statistical Analyses}

Categorical variables were described using numbers and percentages and quantitative variables were described using means and standard deviations, as appropriate. Comparisons between older patients in the geriatric acute care unit and the long-term care and nursing home and between patients who chose telephone calls and video calls were performed using chi-square tests for qualitative variables (or the exact Fisher test where appropriate), and the Student $t$ test was used for quantitative variables (or the Mann-Whitney $U$ test where 
appropriate). $P$ values <.05 were considered significant. All statistical analyses were performed with SPSS version 20 (IBM Corporation).

\section{Availability of Data and Materials}

Patient level data are freely available from the co-corresponding author at Cedric.Annweiler@chu-angers.fr after notification and authorization of the competent authorities. There is no personal identification risk with these anonymized raw data.

\section{Results}

We invited 163 older adults to take part in the study; 132 $(80.1 \%)$ agreed to participate and were included in the study. The age range of the 132 participants was 66 to 103 years (mean age 88.2 years, SD 6.2); 78 (59.1\%) were women.
As illustrated in Table 1, the participants tended to favor telephone calls $(73 / 132,55.3 \%)$ over video calls (59/132, $44.7 \%)$. The satisfaction degrees with the two modalities were similar $(46 / 73,87 \%$, with telephone calls versus $47 / 59,89 \%$, with video calls, $P=.10)$. There was no effect of age $(P=.97)$ or gender $(P=16)$ on the choice of virtual communication mode.

Patients hospitalized in the geriatric acute care unit were more frequently able to independently establish communication $(24 / 105,22.8 \%)$ than residents institutionalized in the long-term care and nursing home $(1 / 27,3.8 \%, P=.03)$ and they were more able to independently establish communication by telephone call $(22 / 73,30.1 \%)$ than by video call $(3 / 59,5.1 \% ; P<.001)$. Moreover, patients hospitalized in the geriatric acute care unit were more often satisfied with the communication $(73 / 79,92 \%)$ than residents of the long-term care and nursing home (20/27, $74 \% ; P=.02)$.

Table 1. Characteristics of the study participants $(\mathrm{N}=132)$.

\begin{tabular}{|c|c|c|c|c|c|c|c|}
\hline \multirow[t]{2}{*}{ Characteristic } & \multirow{2}{*}{$\begin{array}{l}\text { Whole cohort } \\
(\mathrm{N}=132)\end{array}$} & \multicolumn{3}{|c|}{ Preferred virtual communication mode } & \multicolumn{3}{|c|}{ Location of confinement } \\
\hline & & $\begin{array}{l}\text { Telephone call } \\
(\mathrm{n}=73)\end{array}$ & $\begin{array}{l}\text { Video call } \\
(\mathrm{n}=59)\end{array}$ & $P$ value $^{\mathrm{a}}$ & $\begin{array}{l}\text { Geriatric acute } \\
\text { care unit } \\
(\mathrm{n}=105)\end{array}$ & $\begin{array}{l}\text { Long-term care } \\
\text { and nursing } \\
\text { home }(\mathrm{n}=27)\end{array}$ & $P$ value $^{\mathrm{a}}$ \\
\hline \multicolumn{8}{|l|}{ Sociodemographic data } \\
\hline Age (years), mean (SD) & $88.2(6.2)$ & $88.2(5.7)$ & $88.2(6.7)$ & .97 & $88.8(5.4)$ & $85.8(8.1)$ & .08 \\
\hline Female gender, $\mathrm{n}(\%)$ & $78(59.1)$ & $39(53.4)$ & $39(66.1)$ & .16 & $57(54.3)$ & $21(77.8)$ & .03 \\
\hline \multicolumn{8}{|l|}{ Communication with relatives, $\mathrm{n}(\%)$} \\
\hline $\begin{array}{l}\text { Capability of independently estab- } \\
\text { lishing communication }{ }^{b}\end{array}$ & $25(19.1)$ & $22(30.1)$ & $3(5.2)$ & $<.001$ & $24(22.8)$ & $1(3.8)$ & .03 \\
\hline Choice of telephone call & $73(55.3)$ & $\mathrm{N} / \mathrm{A}^{\mathrm{c}}$ & N/A & N/A & $61(58.1)$ & $12(44.4)$ & .28 \\
\hline $\begin{array}{l}\text { High degree of satisfaction (Likert } \\
\text { scale score } \geq 5 / 6 \text { ) }\end{array}$ & $93(87.7)$ & $46(86.8)$ & $47(88.7)$ & $>.99$ & $73(92.4)$ & $20(74.1)$ & .02 \\
\hline
\end{tabular}

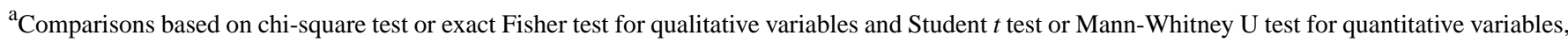
as appropriate.

${ }^{\mathrm{b}}$ Data missing for 1 participant in the long-term care and nursing home.

${ }^{\mathrm{c}} \mathrm{N} / \mathrm{A}$ : not applicable.

${ }^{\mathrm{d}}$ Data missing for 26 participants in the geriatric acute care unit.

In the subgroup analyses (Table 2), older patients chose telephone calls and video calls at similar frequencies when they were hospitalized in the geriatric acute care unit $(61 / 106,57.5 \%$ and $44 / 106,41.5 \%$, respectively) or institutionalized in the long-term care and nursing home $(12 / 27,44.4 \%$, and $12 / 27$, $55.6 \%$, respectively). In the geriatric acute care unit, the satisfaction degrees were similar for telephone calls (40/41, $98 \%)$ and video calls $(33 / 38,87 \%)$ in older patients $(P=.10)$. Conversely, in the long-term care and nursing home, residents were more often satisfied with the use of video calls to communicate with their relatives $(14 / 15,93 \%$, versus $6 / 12$, $50 \%, P=.02$ ) (Table 2). 
Table 2. Subgroup analyses according to confinement place $(\mathrm{N}=132)$.

\begin{tabular}{|c|c|c|c|c|c|c|}
\hline \multirow[t]{2}{*}{ Characteristic } & \multicolumn{3}{|c|}{ Patients in the geriatric acute care unit } & \multicolumn{3}{|c|}{ Residents in the long-term care and nursing home } \\
\hline & $\begin{array}{l}\text { Choice of telephone } \\
\text { call }(\mathrm{n}=61)\end{array}$ & $\begin{array}{l}\text { Choice of video call } \\
(n=44)\end{array}$ & $P$ value $^{\mathrm{a}}$ & $\begin{array}{l}\text { Choice of telephone } \\
\text { call }(n=12)\end{array}$ & $\begin{array}{l}\text { Choice of video } \\
\text { call }(n=15)\end{array}$ & $P$ value $^{\mathrm{a}}$ \\
\hline \multicolumn{7}{|l|}{ Sociodemographic data } \\
\hline Age (years), mean (SD) & $88.5(5.6)$ & $89.3(5.2)$ & .49 & $86.8(6.1)$ & $85.0(9.6)$ & .59 \\
\hline Female gender, $\mathrm{n}(\%)$ & $31(51)$ & $26(59)$ & .43 & $8(67)$ & $13(87)$ & .36 \\
\hline \multicolumn{7}{|l|}{ Communication with relatives, $\mathrm{n}(\%)$} \\
\hline $\begin{array}{l}\text { Capability of independently estab- } \\
\text { lishing communication }{ }^{\mathrm{b}}\end{array}$ & $22(36)$ & $2(5)$ & $<.001$ & $0(0)$ & $1(7)$ & $>.99$ \\
\hline $\begin{array}{l}\text { High degree of satisfaction } \\
(\geq 5 / 6)^{c}\end{array}$ & $40(98)$ & $33(87)$ & .10 & $6(50)$ & $14(93)$ & .02 \\
\hline
\end{tabular}

${ }^{\mathrm{a}}$ Comparisons based on chi-square test or exact Fisher test for qualitative variables and Student $t$ test or Mann-Whitney U test for quantitative variables, as appropriate.

${ }^{\mathrm{b}}$ Data missing for 1 participant in the long-term care and nursing home.

${ }^{\mathrm{c}}$ Data missing for 26 participants in the geriatric acute care unit.

\section{Discussion}

\section{Principal Results}

We found that older adults confined to health care settings (ie, a geriatric acute care unit or long-term care and nursing home) were more often independently able to perform telephone calls than video calls, and they tended to use the telephone more often to communicate with their relatives. Their levels of satisfaction were similar with both communication supports, and satisfaction was even greater with video calls among residents of the long-term care and nursing home when they received assistance to establish communication.

\section{Limitations}

Our study has some limitations. First, the study was monocentric, which limits the representativeness of the study population even if we were able to include a relatively high number of participants. Second, the results should be interpreted with caution because some confounding factors such as cognition and mood were not assessed. Larger, and if possible prospective, studies should be conducted on different population groups to better understand the need for video calls and their effects on loneliness, social isolation, and quality of life in older adults.

\section{Comparison With Prior Work}

The global confinement during the COVID-19 pandemic has highlighted the importance of preventing social isolation and loneliness in older adults [1,2], as social disconnection is associated with increased anxiety and depression [10] and loneliness is associated with increased risks of health disorders, including major neurocognitive disorders [11]. Access to social technologies has been widely proposed to reduce social isolation during the pandemic $[8,12]$, although uncertainty remains about efficacy of video call interventions to reduce loneliness in older adults [13]. Despite this, studies focusing on these technological interventions among frail older adults remain rare [14], and to our knowledge, no study has evaluated the acceptance and preferences of older adults regarding these interventions.
However, there is some evidence that a weak digital culture and eventual impairments may complicate the use of virtual communication modes by older adults [15].

Technological acceptance is a balance between perceived usefulness and perceived simplicity of use [16], to which is added the quality of the output (ie, the way in which the system performs the expected task [17]). A model of technology acceptance dedicated to older adults brings together 10 factors influencing the acceptance of the technology: the value (utility), usability (perceived simplicity), affordability, accessibility, technical support, social support, emotion (output quality), independence, experience, and confidence [15]. In our study, pre-experience (ie, perceived utility and perceived simplicity of use, reflected by the choice of communication mode) and post-experience perceptions (ie, output quality, reflected by the satisfaction degree) were different between geriatric acute care unit patients and long-term care and nursing home residents. In our study, the preference for telephone calls (with $55 \%$ of participants making this choice) is likely due to the participants' pre-experience of the perceived simplicity of this device compared to video calls, which are more often misunderstood and less often used by people in this older generation. In addition, the postexperience perception differed between geriatric acute care unit patients and long-term care and nursing home residents, with a higher degree of satisfaction in the geriatric acute care unit than in the long-term care and nursing home $(73 / 29,92 \%$, vs $20 / 27,74 \% ; P=.02)$. One possible explanation is that the proportion of older adults who were unable to establish communication by themselves was higher in the long-term care and nursing home $(25 / 26,96 \%)$ than in the geriatric acute care unit $(81 / 105,77.1 \% ; P=.03)$. It therefore appears that the pre-experience was unbalanced by the importance given to the perceived ease of use compared to the perceived usefulness of adding video to the call. On the other hand, when older adults in the long-term care and nursing home chose the video calls, generally with assistance establishing the communication, their satisfaction degree was higher with the video calls, which shows that their post-experience was modified 
and could possibly modify their future choices and communication habits.

We also found that a greater proportion of older adults needed assistance to use video calls $(56 / 59,94.8 \%)$ than to use telephone calls $(51 / 73,69.9 \%, P<.001)$. Previous literature has emphasized the importance of offering accessible communication systems, and sustained efforts should be pursued to simplify communication technologies, particularly video calls $[14,18]$. It would also be interesting to support or adapt these communication technologies for people who have communication issues. Technology may provide support for this.

\section{Conclusions}

Older adults in a geriatric acute care unit and a long-term care and nursing home were more independently able to make telephone calls than video calls, and they tended to use the telephone more often than video. However, their post-experience satisfaction with video calls was high. This cross-sectional study contributes to understanding the acceptance and the challenges of frail older adults regarding video calls.

\section{Acknowledgments}

GS is supported by a postdoctoral grant from Research Center on Autonomy and Longevity, University Hospital of Angers, France (2019-2020). The sponsors had no role in the design and conduct of the study, in the collection, management, analysis, and interpretation of the data, or in the preparation, review, or approval of the manuscript. The authors wish to thank Tikeasy and the Fondation Hôpitaux de Paris Hôpitaux de France for the loan of the tablets for the video calls. The authors also thank the TOVID study group: Françoise Angebault (Saint Nicolas University Hospital, Angers, France), Cédric Annweiler (Department of Geriatric Medicine, University Hospital, and School of Medicine, Health Faculty, University of Angers, Angers, France), Marine Asfar (Department of Geriatric Medicine, University Hospital, Angers, France), Melinda Beaudenon (Department of Geriatric Medicine, University Hospital, Angers, France), France Bertrand (School of Medicine, Health Faculty, University of Angers, Angers, France), Marie Brichard (School of Medicine, Health Faculty, University of Angers, Angers, France), Jean Barré (Department of Geriatric Medicine, University Hospital, Angers, France), Gabriel Bordier (School of Medicine, Health Faculty, University of Angers, Angers, France), Inès Bouchet (School of Medicine, Health Faculty, University of Angers, Angers, France), Aude Bouchevreau (School of Medicine, Health Faculty, University of Angers, Angers, France), Antoine Brangier (Department of Geriatric Medicine, University Hospital, Angers, France), Adeline Chanson (School of Medicine, Health Faculty, University of Angers, Angers, France), Isabelle Chausson (Saint Nicolas University Hospital, Angers, France), Linda Collet (School of Medicine, Health Faculty, University of Angers, Angers, France), Marie Daussy (School of Medicine, Health Faculty, University of Angers, Angers, France), Luc Delneste (School of Medicine, Health Faculty, University of Angers, Angers, France), Elise Dolbeau (School of Medicine, Health Faculty, University of Angers, Angers, France), Maxime Dronne (School of Medicine, Health Faculty, University of Angers, Angers, France), Brune Du Plessis (School of Medicine, Health Faculty, University of Angers, Angers, France), Guillaume Duval (Department of Geriatric Medicine, University Hospital, Angers, France), Lydia Gabard (School of Medicine, Health Faculty, University of Angers, Angers, France), Jennifer Gautier (Department of Geriatric Medicine, University Hospital, Angers, France), Anne Guyard (Department of Geriatric Medicine, University Hospital, Angers, France), Tiphaine Housty (Department of Geriatric Medicine, University Hospital, Angers, France), Valentin Jouanno (School of Medicine, Health Faculty, University of Angers, Angers, France), Clémence Le Ho (School of Medicine, Health Faculty, University of Angers, Angers, France), Cassandra Lepoureau (School of Medicine, Health Faculty, University of Angers, Angers, France), Sébastien Lléonart, Mélanie Loison (School of Medicine, Health Faculty, University of Angers, Angers, France), Jocelyne Loison (Department of Geriatric Medicine, University Hospital, Angers, France), Laurence Loufrani (Saint Nicolas University Hospital, Angers, France), Emilie Lucas (Department of Geriatric Medicine, University Hospital, Angers, France), Camille Macé (School of Medicine, Health Faculty, University of Angers, Angers, France), Naomi Maire (School of Medicine, Health Faculty, University of Angers, Angers, France), Clément Marla (School of Medicine, Health Faculty, University of Angers, Angers, France), Nathalie Martin (Saint Nicolas University Hospital, Angers, France), Andréa Mathieu (School of Medicine, Health Faculty, University of Angers, Angers, France), Morgane Mauger (School of Medicine, Health Faculty, University of Angers, Angers, France), Sahondra Mayet (School of Medicine, Health Faculty, University of Angers, Angers, France), Justine Menon (School of Medicine, Health Faculty, University of Angers, Angers, France), Frédéric Messian (School of Medicine, Health Faculty, University of Angers, Angers, France), Constance Moucheboeuf (School of Medicine, Health Faculty, University of Angers, Angers, France), Antoine Mussard (School of Medicine, Health Faculty, University of Angers, Angers, France), Frédéric Noublanche (Department of Geriatric Medicine, University Hospital, Angers, France), Antoine Octau (School of Medicine, Health Faculty, University of Angers, Angers, France), Marie Otekpo (Department of Geriatric Medicine, University Hospital, Angers, France), Capucine Phuong-Anh Carion (School of Medicine, Health Faculty, University of Angers, Angers, France), Valentin Poile (School of Medicine, Health Faculty, University of Angers, Angers, France), Lisa Quentin (School of Medicine, Health Faculty, University of Angers, Angers, France), Anne Renaudin (Department of Geriatric Medicine, University Hospital, Angers, France), Gwladys Roger (School of Medicine, Health Faculty, University of Angers, Angers, France), Quentin Rousseau (School of Medicine, Health Faculty, University of Angers, Angers, France), Florence Roult (Department of Geriatric Medicine, University Hospital, Angers, France), Guillaume Sacco (Department of Geriatric Medicine, University Hospital, Angers, France), Claire Simon (School of Medicine, Health Faculty, University of Angers, Angers, France), Ophélie Simon (School of Medicine, Health Faculty, University of Angers, Angers, France), Romain Simon (Department of Geriatric Medicine, University Hospital, Angers, 
France), Romane Surget (School of Medicine, Health Faculty, University of Angers, Angers, France), Violette Tourrel (School of Medicine, Health Faculty, University of Angers, Angers, France), Lise Trubert (School of Medicine, Health Faculty, University of Angers, Angers, France), Inès Watteaux (School of Medicine, Health Faculty, University of Angers, Angers, France).

\section{Authors' Contributions}

CA has full access to all of the data in the study, takes responsibility for the data, the analyses and interpretation, and has the right to publish any and all data, separate and apart from the attitudes of the sponsors. CA supervised the study and provided administrative, technical, and material support. GS and CA conceived and designed the study, analyzed and interpreted the data, drafted the manuscript, and provided statistical expertise. SL and RS provided critical revision of the manuscript for important intellectual content. All authors have read and approved the manuscript.

\section{Conflicts of Interest}

None declared.

\section{References}

1. Armitage R, Nellums LB. COVID-19 and the consequences of isolating the elderly. Lancet Public Health 2020 May;5(5):e256. [doi: 10.1016/s2468-2667(20)30061-x]

2. Cudjoe TK, Kotwal AA. "Social Distancing" Amid a Crisis in Social Isolation and Loneliness. J Am Geriatr Soc 2020 Jun 15;68(6):E27-E29 [FREE Full text] [doi: 10.1111/jgs.16527] [Medline: 32359072]

3. Brooks SK, Webster RK, Smith LE, Woodland L, Wessely S, Greenberg N, et al. The psychological impact of quarantine and how to reduce it: rapid review of the evidence. Lancet 2020 Mar 14;395(10227):912-920 [FREE Full text] [doi: 10.1016/S0140-6736(20)30460-8] [Medline: 32112714]

4. Hemberg J, Santamäki Fischer R. A Window Toward the World Older Adults' Experiences of Becoming in Health and Developing as Human Beings Through Interacting With Others Using Real Video Communication. Holist Nurs Pract 2018;32(2):90-97. [doi: 10.1097/hnp.0000000000000254]

5. Chipps J, Jarvis MA, Ramlall S. The effectiveness of e-Interventions on reducing social isolation in older persons: A systematic review of systematic reviews. J Telemed Telecare 2017 Dec;23(10):817-827. [doi: 10.1177/1357633X17733773] [Medline: 28958209]

6. Gardiner C, Geldenhuys G, Gott M. Interventions to reduce social isolation and loneliness among older people: an integrative review. Health Soc Care Community 2018 Mar;26(2):147-157. [doi: 10.1111/hsc.12367] [Medline: 27413007]

7. Poscia A, Stojanovic J, La Milia DI, Duplaga M, Grysztar M, Moscato U, et al. Interventions targeting loneliness and social isolation among the older people: An update systematic review. Exp Gerontol 2018 Feb;102:133-144. [doi: 10.1016/j.exger.2017.11.017] [Medline: 29199121]

8. Eghtesadi M. Breaking Social Isolation Amidst COVID-19: A Viewpoint on Improving Access to Technology in Long-Term Care Facilities. J Am Geriatr Soc 2020 May;68(5):949-950 [FREE Full text] [doi: 10.1111/jgs.16478] [Medline: 32277470]

9. Ruopp MD. Overcoming the Challenge of Family Separation From Nursing Home Residents During COVID-19. J Am Med Dir Assoc 2020 Jul;21(7):984-985 [FREE Full text] [doi: 10.1016/j.jamda.2020.05.022] [Medline: $\underline{32536554]}$

10. Santini ZI, Jose PE, York Cornwell E, Koyanagi A, Nielsen L, Hinrichsen C, et al. Social disconnectedness, perceived isolation, and symptoms of depression and anxiety among older Americans (NSHAP): a longitudinal mediation analysis. Lancet Public Health 2020 Jan;5(1):e62-e70 [FREE Full text] [doi: 10.1016/S2468-2667(19)30230-0] [Medline: 31910981]

11. Sutin A, Stephan Y, Luchetti M, Terracciano A. Loneliness and Risk of Dementia. J Gerontol Ser B 2018 Nov 16;Innovation in Aging, Volume 2(suppl_1):966-967. [doi: 10.1093/geroni/igy031.3581]

12. Simard J, Volicer L. Loneliness and Isolation in Long-term Care and the COVID-19 Pandemic. J Am Med Dir Assoc 2020 Jul;21(7):966-967 [FREE Full text] [doi: 10.1016/j.jamda.2020.05.006] [Medline: 32505516]

13. Chopik WJ. The Benefits of Social Technology Use Among Older Adults Are Mediated by Reduced Loneliness. Cyberpsychol Behav Soc Netw 2016 Sep;19(9):551-556 [FREE Full text] [doi: 10.1089/cyber.2016.0151] [Medline: 27541746]

14. Neves BB, Franz RL, Munteanu C, Baecker R. Adoption and feasibility of a communication app to enhance social connectedness amongst frail institutionalized oldest old: an embedded case study. Inf Commun Soc 2017 Jul 13;21(11):1681-1699. [doi: 10.1080/1369118x.2017.1348534]

15. Lee C, Coughlin JF. Perspective: Older Adults' Adoption of Technology: An Integrated Approach to Identifying Determinants and Barriers. J Prod Innov Manag 2014 Jun 03;32(5):747-759. [doi: 10.1111/jpim.12176]

16. Chin WW, Johnson N, Schwarz A. A Fast Form Approach to Measuring Technology Acceptance and Other Constructs. MIS Q 2008;32(4):687. [doi: $10.2307 / 25148867]$

17. Venkatesh V, Davis FD. A Theoretical Extension of the Technology Acceptance Model: Four Longitudinal Field Studies. Manage Sci 2000 Feb;46(2):186-204. [doi: 10.1287/mnsc.46.2.186.11926]

18. Barbosa Neves B, Franz R, Judges R, Beermann C, Baecker R. Can Digital Technology Enhance Social Connectedness Among Older Adults? A Feasibility Study. J Appl Gerontol 2019 Jan;38(1):49-72. [doi: 10.1177/0733464817741369] [Medline: 29166818] 


\section{Abbreviations}

CNIL: National Commission for Information Technology and Civil Liberties

TOVID: Telephony Or Videophony for Isolated elderly

Edited by G Eysenbach; submitted 29.06.20; peer-reviewed by C Miranda, I David; comments to author 15.07.20; revised version received 17.07.20; accepted 22.07.20; published 18.09.20

Please cite as:

Sacco $G$, Lléonart S, Simon R, Noublanche F, Annweiler C, TOVID Study Group

Communication Technology Preferences of Hospitalized and Institutionalized Frail Older Adults During COVID-19 Confinement:

Cross-Sectional Survey Study

JMIR Mhealth Uhealth 2020;8(9):e21845

URL: http://mhealth.jmir.org/2020/9/e21845/

doi: $10.2196 / 21845$

PMID: $\underline{32896832}$

(C) Guillaume Sacco, Sébastien Lléonart, Romain Simon, Frédéric Noublanche, Cédric Annweiler, TOVID Study Group. Originally published in JMIR mHealth and uHealth (http://mhealth.jmir.org), 18.09.2020. This is an open-access article distributed under the terms of the Creative Commons Attribution License (https://creativecommons.org/licenses/by/4.0/), which permits unrestricted use, distribution, and reproduction in any medium, provided the original work, first published in JMIR mHealth and uHealth, is properly cited. The complete bibliographic information, a link to the original publication on http://mhealth.jmir.org/, as well as this copyright and license information must be included. 